\title{
Suplementação Energética na Recria de Fêmeas de Corte em Pastagem Cultivada de Inverno. Produção Animal
}

\section{Fabiana Kellermann de Freitas ${ }^{1}$, Marta Gomes da Rocha ${ }^{2}$, João Restle ${ }^{3}$, Ivan Luiz Brondani ${ }^{4}$, Stefani Macari ${ }^{5}$, Éverton Pujol Guterres ${ }^{6}$, Carolina da Silveira Nicoloso ${ }^{5}$}

\begin{abstract}
RESUMO - Foi avaliado o desempenho de novilhas de corte em pastagem de aveia preta (Avena strigosa Schreb) mais azevém (Lolium multiflorum Lam) submetidas aos seguintes tratamentos: 'Sem Suplemento'- animais exclusivamente em pastagem; 'Crescente' animais recebendo níveis crescentes de suplemento $(0,3 ; 0,6 ; 0,9 ; 1,2$ a 1,5\% do peso vivo [PV]) durante o ciclo da pastagem; 'Fixo' - animais recebendo $0,9 \%$ do PV de suplemento durante todo o ciclo da pastagem; e 'Decrescente' - animais recebendo níveis decrescentes de suplemento $(1,5 ; 1,2 ; 0,9 ; 0,6$ a $0,3 \%$ do PV) durante o ciclo da pastagem. O suplemento utilizado foi farelo de trigo. O período de pastejo foi de 13 de julho a 01 de novembro e o método de pastejo foi contínuo com lotação variável. As variáveis estudadas (ganho de peso médio diário [GMD], condição corporal [CC], carga animal [CA] e ganho de peso por área [GPA] não foram afetadas pela suplementação ou variação do nível de suplemento. O GMD, CA e GPA variaram com o decorrer do ciclo da pastagem; o GMD apresentou comportamento quadrático, sendo crescente até o $62^{\circ}$ dia $\left(\mathrm{GMD}=0,360+0,025\right.$ dia- $\left.0,0002 \mathrm{dia}^{2} ; \mathrm{R}^{2}=0,59\right)$, com valor médio de $0,937 \mathrm{~kg} / \mathrm{animal} / \mathrm{dia}$. A CA apresentou aumento linear durante o período de pastejo, enquanto a CC não variou com o decorrer do período de pastejo.
\end{abstract}

Palavras-chave: Avena strigosa, farelo de trigo, Lolium multiflorum, pastejo contínuo

\section{Energy Supplementation on Rearing Beef Female in Winter Cultivated Pasture. Animal Production}

\begin{abstract}
The performance of beef heifers in black oat (Avena strigosa Schreb.) plus ryegrass (Lolium multiflorum Lam.) pasture was evaluated in this trial. The treatments evaluated were: 'No Supplement'- animals in black oat plus ryegrass pasture; 'Increasing' - animals in black oat plus ryegrass pasture, receiving increasing levels of supplement (wheat bran): $0.3 ; 0.6 ; 0.9 ; 1.2$ to $1.5 \%$ body weight (BW) during the pasture cycle; 'Fixed' - animals in black oat plus ryegrass pasture, fed $0.9 \%$ BW of supplement during all pasture cycle; and 'Decreasing' - animals in black oat plus ryegrass pasture, receiving decreasing levels of supplement: 1.5; 1.2; 0.9; 0.6 a $0.3 \%$ of BW during the pasture cycle. The grazing period was within July 13 to November $1^{\text {st }}$ and the grazing method was continuous with variable stocking rate. The variables invetigated were: average daily gain (ADG), body condition (BC), stocking rate (SR) and per area weight gain (AWG). Supplementation or the different supplement level s showed no effect on the evaluated traits. ADG, SR and AWG changed with the pasture cycle. ADG had quadratic behavior, increasing until $62^{\circ}$ day, represented by the following equation: $\mathrm{ADG}=0.360+0.025 \mathrm{day}-$ 0.0002 day $2\left(\mathrm{R}^{2}=0.59\right)$. The mean ADG value was $0.937 \mathrm{~kg} /$ animal $/$ day. SR increased linearly during the grazing period, whereas no effect of grazing period on $\mathrm{BC}$ was detected.
\end{abstract}

Key Words: Avena strigosa, wheat bran, Lolium multiflorum, continuous grazing

\section{Introdução}

A alimentação do rebanho bovino de cria no Rio Grande do Sul é composta basicamente por pastagens nativas ou cultivadas, com as técnicas alimentares mais intensivas, como suplementação e confinamento, utilizadas para os machos. Alguns objetivos na recria de fêmeas, como o acasalamento aos 14 meses, no entanto, exigem o uso de suplementação e pastagem cultivada, minimizando os efeitos climáticos aos quais as pastagens cultivadas estão submetidas, que prejudicam seu estabelecimento, crescimento e, conseqüentemente, a carga animal suportada.

Para novilhas em recria atingirem peso adequado, ao final do ciclo das pastagens de inverno, é necessário assegurar determinado ganho individual, cujo valor é dependente do peso vivo dos animais no início do pastejo. O ganho médio diário dos animais em pastejo

\footnotetext{
${ }^{1}$ Eng. Agr. Aluna do Programa de Pós-Graduação em Zootecnia, Universidade Federal de Santa Maria. E.mail: fkfreitas@hotmail.com 2 Eng. Agr. Dra., Prof. Adjunto do Depto. de Zootecnia, UFSM. E.mail: tata@via-rs.net. Rua Tuiuti, 1554/201, CEP: 97105-662, Santa Maria, RS ${ }^{3}$ Eng. Agr. PhD, Prof. Titular do Depto. de Zootecnia, UFSM. E.mail: jorestle@ccr.ufsm.br

${ }^{4}$ Zoot. Dr., Prof. Adjunto do Depto. de Zootecnia, UFSM. E.mail: brondani@ccr.ufsm.br

${ }^{5}$ Aluno do curso de Graduação em Zootecnia, UFSM. E.mail: setorforrageiras@bol.com.br

${ }^{6}$ Aluno do curso de Graduação em Medicina Veterinária, UFSM. E.mail: setorforrageiras@bol.com.br
} 
não é uniforme ao longo do ciclo da pastagem, mesmo mantendo oferta de forragem adequada (Frizzo et al., 2003), em decorrência de mudanças comportamentais dos animais em resposta ao novo ambiente de pastejo e da estrutura da pastagem, com maior proporção de colmos no final do ciclo das forrageiras, determinando redução no consumo voluntário de matéria seca (Pilau et al., 2003). Espécies forrageiras caracterizam-se pela heterogeneidade da distribuição da forragem ao longo do seu ciclo, tanto em qualidade quanto em quantidade. A pastagem de aveia mais azevém atende às demandas de proteína bruta para novilhas em recria (Rocha et al., 2003), mas não proporciona suprimento energético adequado ao desempenho individual dos animais (Santos et al., 2005). Por outro lado, a carga animal não pode ser fixa, uma vez que o ambiente que suporta o crescimento das forrageiras é variável na oferta de recursos como água, temperatura, luz e nutrientes, entre outros, proporcionando resposta variável ao uso de suplementos energéticos em pastagens temperadas, podendo ou não ocorrer efeito aditivo no ganho de peso em resposta ao suplemento ou aumento na carga animal, em função do efeito substitutivo do consumo de forragem pelo de suplemento. A utilização de uma quantidade fixa de suplemento tem efeitos variáveis no desempenho individual e na carga animal no decorrer do ciclo da forrageira (Santos et al., 2005). A substituição de parte do consumo de forragem pelo consumo de suplemento pode elevar a capacidade de carga até valores que, sem redução acentuada do ganho por indivíduo, possibilitem melhorar a produção animal por unidade de área (Rocha et al., 2003 b).

Para manter ganho individual e carga animal sem variações elevadas, facilitando o planejamento da atividade pecuária, uma alternativa seria variar os níveis de suplementação no decorrer do período de pastejo, com efeitos esperados sobre a economicidade da atividade e a redução no manejo, utilizando-se menor variação na carga animal. O conhecimento do tipo e da quantidade do suplemento energético a ser fornecido aos animais contribui para maior eficiência de utilização da suplementação. Quando as necessidades de proteína degradável no rúmen são satisfeitas, os efeitos associativos negativos da suplementação com amido são improváveis (Bodine et al., 2001). Para maximizar a utilização de gramíneas forrageiras temperadas, com o fornecimento de um único suplemento, o farelo de trigo parece ser um pouco mais adequado que o grão de milho. A disponibilidade e o custo podem constituir as principais considerações na escolha entre estes dois suplementos (Galloway et al., 1991).

O objetivo neste trabalho foi avaliar a influência da variação do nível de suplementação energética no desempenho de novilhas de corte em recria, mantidas em pastagem cultivada de inverno.

\section{Material e Métodos}

O experimento foi realizado em área pertencente ao Departamento de Zootecnia da Universidade Federal de Santa Maria - UFSM, localizada na Depressão Central do Rio Grande do Sul, com altitude de 95

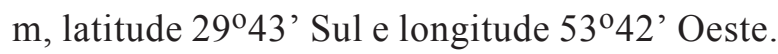

$\mathrm{O}$ solo da área experimental pertence à unidade de mapeamento São Pedro e é classificado como Argissolo Vermelho Distrófico Arênico (EMBRAPA, 1999), com relevo levemente ondulado, solos profundos e textura superficial arenosa, bem drenados e naturalmente ácidos. O clima da região, conforme classificação de Köppen (Moreno, 1961), é Cfa (subtropical úmido).

A área experimental foi dividida em doze potreiros, com área média de 0,97 ha, totalizando 11,7 ha, e mais uma área contígua de 4,6 ha para permanência dos animais reguladores. A cobertura vegetal, constituída por resteva de sorgo, foi dessecada, aplicando-se 2 $\mathrm{kg} /$ ha de herbicida Glifosato.

A pastagem foi implantada por plantio direto nos dias oito e nove de maio de 2003, utilizando-se uma mistura de duas espécies forrageiras, aveia (Avena strigosa Schreb) mais azevém (Lolium multiflorum Lam), na densidade de $100 \mathrm{~kg} /$ ha de semente de aveia e $50 \mathrm{~kg} / \mathrm{ha}$ de semente de azevém. A semente de azevém foi distribuída $60 \%$ em linha e, posteriormente, $40 \%$ a lanço. A distância entre linhas, tanto para aveia como azevém, foi de $17 \mathrm{~cm}$. A adubação foi de $250 \mathrm{~kg} / \mathrm{ha}$ de adubo organo-mineral de fórmula 7-1010. Em cobertura, foram aplicados $127 \mathrm{~kg} / \mathrm{ha}$ de nitrogênio $(\mathrm{N})$ na forma de uréia, em três aplicações.

Foi avaliado o desempenho produtivo de novilhas em pastejo sob variações do nível de suplementação energética. Os tratamentos testados em pastagem de aveia e azevém, foram: 'Sem Suplemento'- animais exclusivamente em pastagem; 'Crescente' - animais recebendo níveis crescentes de suplemento $(0,3 ; 0,6$; 0,$9 ; 1,2$ a $1,5 \%$ do peso vivo [PV]) durante o ciclo da 
pastagem; 'Fixo' - animais recebendo $0,9 \%$ do PV de suplemento durante todo o ciclo da pastagem; e 'Decrescente' - animais recebendo níveis decrescentes de suplemento $(1,5 ; 1,2 ; 0,9 ; 0,6$ a $0,3 \%$ do PV) durante o ciclo da pastagem. A mudança dos níveis de suplemento foi realizada nas seguintes datas: 13/07 (período 1); 05/08 (período 2); 24/08 (período 3); 14/09 (período 4) e 05/10 (período 5). Animais no tratamento 'Decrescente', por exemplo, receberam $1,5 \%$ do PV no período de $13 / 07$ a 04/08; $1,2 \%$ do PV no período de $05 / 08$ a 23/08; $0,9 \%$ do PV no período de 24/08 a 13/09; 0,6\% do PV no período de 14/09 a $04 / 10$ e $0,3 \%$ do PV no período de $05 / 10$ a $01 / 11$.

O suplemento utilizado foi farelo de trigo, fornecido diariamente às $14 \mathrm{~h}$ em quantidade ajustada de acordo com a mudança dos níveis de suplemento e com a carga animal mantida nos potreiros, conforme estimativa de ganho dos animais.

O método de pastejo foi contínuo, utilizando-se três novilhas teste e um número variável de reguladoras por repetição. As primeiras permaneceram nos piquetes durante todo o período de utilização da pastagem, enquanto as reguladoras foram utilizadas para adequar a carga animal dos potreiros pela técnica put-and-take (Mott \& Lucas, 1952), procurando-se manter a mesma massa de forragem em todos os tratamentos. As massas de forragem pretendidas variaram de $1.000 \mathrm{~kg} / \mathrm{ha}$ de MS, no início do período de pastejo, $1.300 \mathrm{~kg} / \mathrm{ha}$ de MS, na fase intermediária do ciclo das forrageiras, até $1.500 \mathrm{~kg} /$ ha de MS no final do período de utilização da pastagem. Para que as novilhas se adaptassem à mudança de alimentação e fossem atingidos os níveis de suplemento desejados, os animais passaram por um período de adaptação de sete dias (04 a 12/07) antes do início do período experimental.

O período de estabelecimento da pastagem foi de 56 dias. O período de pastejo foi de 13 de julho a 01 de novembro, totalizando 112 dias. Foram utilizadas 80 novilhas cruza Charolês-Nelore. Os animais teste pertenciam aos grupos genéticos 11/16 Charolês/ Nelore, 5/8 Charolês/Nelore e 5/8 Nelore/Charolês oriundos do rebanho do Setor de Bovinocultura de Corte do Departamento de Zootecnia da UFSM e apresentavam idade e peso médio iniciais de oito meses e 149,3 kg, respectivamente, em julho de 2003.

As pesagens dos animais foram realizadas em intervalo de 21 dias, exceto no último período de avaliação, que foi de 28 dias, respeitando-se jejum prévio de 12 horas em todas as pesagens. As novilhas foram identificadas com brincos e pesadas individualmente, avaliando, em seguida, o seu escore de condição corporal (ECC), por meio de adaptação da metodologia descrita por Lowman et al. (1973) com escores que variam de 1 (muito magro) a 5 (muito gordo).

O controle de endoparasitas foi realizado por meio de dosificações com fosfato de levamisol aos animais quando apresentavam infestação acima de 500 ovos por grama de fezes.

A massa de forragem (MF) foi determinada pela técnica de dupla amostragem, no início do período de pastejo e, posteriormente, a cada 10 dias. Em cada potreiro, foram realizados cinco cortes rente ao solo e 20 estimativas visuais.

Para a determinação da taxa de acúmulo diário de MS (TAD, em kg/ha/dia), foram utilizadas três gaiolas de exclusão ao pastejo por potreiro. A medição da altura da pastagem na inflexão das folhas foi realizada a cada estimativa da MF pela técnica da dupla amostragem com o auxílio de uma régua graduada.

$\mathrm{O}$ valor nutritivo da forragem aparentemente consumida pelos animais foi determinado a partir de análise laboratorial das amostras colhidas por meio de simulação de pastejo (Euclides et al., 1992). As amostras colhidas foram pesadas e secas em estufa com ventilação forçada a $65^{\circ} \mathrm{C}$, por 72 horas; foram pesadas novamente e moídas em moinho tipo Willey, para posteriores análises. Os parâmetros avaliados foram proteína bruta (PB), segundo AOAC (1990), e digestibilidade in vitro da matéria orgânica (DIVMO), de acordo com Tilley \& Terry (1963). O teor de nutrientes digestíveis totais (NDT) foi calculado pelo produto entre a porcentagem de matéria orgânica (\%MO) e a digestibilidade in vitro da matéria orgânica (\%DIVMO), dividido por 100. Pelos resultados de DIVMO, estimou-se o conteúdo de energia metabolizável, adotando-se a fórmula: EM (Mcal/ $\mathrm{kg})=$ DIVMO $\times$ \%MO x 3,652 (para forragem) ou 3,564 (para concentrados) (Maff, 1977).

O ganho médio diário (GMD) dos animais foi obtido pela diferença entre os pesos final e inicial dos animais teste, em cada período experimental, dividida pelo número de dias do período. A carga animal (CA) por período foi estimada pela soma do peso médio dos animais teste com peso médio dos animais reguladores mais o produto do GMD das novilhas teste com o número de dias em que permaneceram no potreiro. 
A produção animal por hectare (GPA) foi obtida pelo produto da taxa de lotação, do GMD das novilhas teste e do número de dias do período.

$\mathrm{O}$ consumo de MS de forragem foi estimado pela diferença entre a produção total de MS de forragem e o somatório da MF no final do período experimental e das perdas de forragem ocorridas durante o período de pastejo. As perdas de forragem foram determinadas pela metodologia proposta por Hillesheim (1987). O consumo estimado de MS em \% do PV foi obtido dividindo-se o consumo de MS de forragem estimado pela CA. A oferta total de forragem foi calculada pelo somatório da oferta de forragem (kg de MS da forragem/100 kg de peso vivo (PV)) mais a oferta de suplemento ( $\mathrm{kg}$ de MS do suplemento/100 kg de PV).

As taxas de substituição e de adição do consumo de suplemento sobre o consumo de forragem foram estimadas a partir do cálculo proposto por Hodgson (1990), em que: substituição = (consumo de matéria seca (MS) de forragem dos animais não-suplementados - consumo de MS da forragem dos animais que recebem suplementação)/consumo de MS do suplemento*100; adição = (consumo total de MS dos animais suplementados - consumo de MS da forragem dos animais não suplementados)/consumo de MS do suplemento* 100 .

O delineamento experimental foi inteiramente casualizado, com quatro tratamentos e três repetições, constituídas por três potreiros. Os resultados foram submetidos à análise de variância e, quando detectadas diferenças, as médias foram comparadas pelo teste Tukey, a 5\% de significância. Para as variáveis que apresentaram correlação significativa com período, foi feita análise de regressão polinomial, empregando-se o pacote estatístico SAS versão 6.08 (1996). O modelo matemático geral referente à análise das variáveis estudadas foi representado por:

$$
\mathrm{Y}_{\mathrm{ijk}}=\mu+\mathrm{l}_{\mathrm{i}}+\rho_{\mathrm{j}}\left(\mathrm{l}_{\mathrm{i}}\right)+\alpha_{\mathrm{k}}+(\mathrm{l} \alpha)_{\mathrm{ik}}+\varepsilon_{\mathrm{ijk}}
$$

em que $Y_{i j k}$ representa as variáveis dependentes; $\mu$ é a média de todas as observações; $\boldsymbol{}_{\mathrm{i}}$, o efeito do i-ésimo tratamento; $\rho_{\mathrm{j}}\left(\mathrm{l}_{\mathrm{i}}\right)$, o efeito da j-ésima repetição dentro do i-ésimo tratamento (erro a); $\alpha_{\mathrm{k}}$, o efeito do k-ésimo período; $(1 \alpha)_{\mathrm{ik}}$, a interação entre o i-ésimo tratamento e o k-ésimo período; e $\varepsilon_{i j k}$, o erro experimental residual (erro b).

\section{Resultados e Discussão}

Na Tabela 1, encontram-se os valores médios de massa de forragem (MF), altura da pastagem, taxa de acúmulo diário de MS (TAD) e oferta total (OT, forragem + suplemento). A suplementação ou a variação do nível de suplemento não afetaram os parâmetros da pastagem (Freitas et al., 2005). A MF aumentou gradativamente de $1.173,0 \mathrm{~kg} / \mathrm{ha}$ de $\mathrm{MS}$, no primeiro período de pastejo, para $2.143,9 \mathrm{~kg} / \mathrm{ha}$ de MS, no último período de pastejo. Com este manejo da MF, procurou-se evitar o alongamento dos entrenós e a elevação precoce do ponto de crescimento da aveia preta (Restle et al., 2000). O valor médio da MF $(1.587,8 \mathrm{~kg})$ atendeu a recomendação de Mott (1984) para maior ganho individual.

Provavelmente, a altura média da pastagem, 17 $\mathrm{cm}$, não restringiu a oportunidade de seleção por parte dos animais em pastejo. Alturas em torno de $18 \mathrm{~cm}$ são as mais adequadas para manejo da aveia, proporcionando os maiores ganhos (Grise et al., 2001). A TAD foi semelhante à média dos últimos anos em trabalhos conduzidos com as mesmas espécies e na mesma área (Frizzo et al., 2003 b; Pilau et al., 2005). O valor médio de OTF, no final do ciclo da pastagem, foi inferior $(\mathrm{P}<0,05)$ ao dos demais períodos de ava-

Tabela 1 - Massa de forragem (MF, kg/ha de MS), altura da pastagem (ALT, cm), taxa de acúmulo diário de $M S(T A D, \mathrm{~kg} / \mathrm{ha} / \mathrm{dia}$ de $M S)$ e oferta total de forragem (OTF, kg MS/100 kg PV) da pastagem de aveia ( $A$. strigosa) mais azevém ( $L$. multiflorum) utilizada por novilhas de corte

Table 1 - Forage mass (FM, kg/ha DM), pasture height (HEl, $\mathrm{cm})$, accumulation daily rate of $D M(A D R, \mathrm{~kg} / \mathrm{ha} /$ day $D M)$ and total forage on offer (TFO, $\mathrm{kg} \mathrm{DM} / 100 \mathrm{~kg}$ LW) of oat (A. strigosa) plus ryegrass (L. multiflorum) pasture grazed by beef heifers

\begin{tabular}{lcccc}
\hline Período & MF & Altura & TAD & OTF \\
Period & $F M$ & Height & ADR & TFO \\
\hline 13/07-04/08 & $1.173,0 \mathrm{~b}$ & $21 \mathrm{a}$ & 42,1 & $8,7 \mathrm{a}$ \\
05/08-23/08 & $1.190,0 \mathrm{~b}$ & $16 \mathrm{~b}$ & 42,6 & $6,5 \mathrm{a}$ \\
$24 / 08-13 / 09$ & $1.336,7 \mathrm{~b}$ & $15 \mathrm{c}$ & 46,4 & $8,7 \mathrm{a}$ \\
14/09-04/10 & $2.112,7 \mathrm{a}$ & $17 \mathrm{~b}$ & 60,9 & $8,7 \mathrm{a}$ \\
05/10-01/11 & $2.126,4 \mathrm{a}$ & $17 \mathrm{~b}$ & 58,8 & $4,6 \mathrm{~b}$ \\
\hline Média (Mean) & $1.587,8$ & 17 & 50,6 & 7,2 \\
\hline CV $(\%)$ & 10,11 & 8,08 & 40,01 & 14,35
\end{tabular}

$a, b, c$ na mesma coluna, diferem entre si $(P<0,05)$.

$a, b, c$ in the same column, differ $(P<.05)$. 
liação, em função da carga animal utilizada para manter a MF nos potreiros experimentais. A OTF média $(7,2)$ foi inferior à obtida por Pilau et al. (2004), de $10 \mathrm{~kg}$ de $\mathrm{MS} / 100 \mathrm{~kg}$ de PV, também em pastagem de aveia mais azevém, e não afetou o desempenho das novilhas, que foi de $0,937 \mathrm{~kg} /$ animal $/$ dia (Figura 1 ).

As novilhas 'Sem suplemento' apresentaram valores de ganho médio diário semelhantes $(\mathrm{P}>0,05)$ aos das suplementadas. O efeito aditivo do uso de suplemento sobre o ganho individual não foi observado $(\mathrm{P}>0,05)$, mesmo com a utilização de farelo de trigo, um suplemento rico em fibra prontamente digestível, que parece ter menor efeito associativo negativo sobre o ambiente ruminal (Figura 1).

Este tipo de suplemento estimula a ruminação e salivação, mantendo o ambiente ruminal satisfatório e favorecendo o ganho individual dos animais (Tambara et al., 1995). Pilau et al. (2004) observaram interação entre período e nível de suplementação com farelo de trigo. No período de adaptação, novilhas recebendo $1 \%$ do PV de suplemento alcançaram GMD 95,78\% superior ao dos animais exclusivamente em pastagem. O efeito aditivo no GMD pode estar associado à menor disponibilidade de forragem neste período.

O GMD também não foi afetado quando houve variação no nível de suplemento consumido ao longo do ciclo da pastagem e o nível adotado em uma fase não resultou em resposta diferente na fase posterior

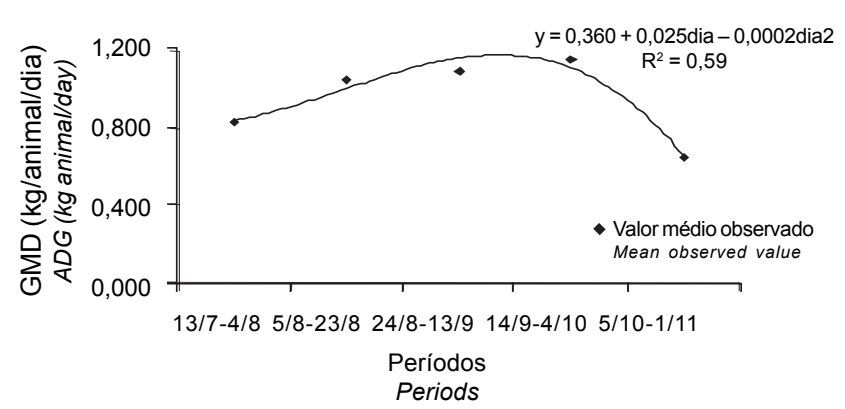

Figura 1 - Ganho médio diário (GMD, kg/an/dia) de noviIhas de corte submetidas à variação do nível de suplementação durante o ciclo da pastagem de aveia ( $A$. strigosa) mais azevém ( $L$. multiflorum).

Figure 1 - Average daily gain (ADG, kg/an/day) of beef heifers on different supplementation levels, during the oat (A. strigosa) plus ryegrass (L. multiflorum) pasture cycle.
$(\mathrm{P}>0,05)$. Portanto, há grande possibilidade de manipulação de níveis de suplemento energético (desde 0,3 a $1,5 \%$ ) no ciclo da pastagem de aveia mais azevém, sem interferência no desempenho individual dos animais.

O GMD oscilou no decorrer do ciclo da pastagem $(\mathrm{P}<0,05)$ e foi melhor representado pela equação quadrática, sendo crescente até o $62^{\circ}$ dia, o que está relacionado às mudanças na estrutura da vegetação e à redução na oferta de forragem + suplemento no final do ciclo das forrageiras, que provavelmente ocasionaram queda no consumo voluntário de MS. Os ganhos foram bastante elevados em todos os tratamentos, possivelmente pela restrição alimentar sofrida pelas novilhas antes do período experimental, que pode ter contribuído também para que os animais mantidos exclusivamente na pastagem tenham conseguido obter da forragem aporte de nutrientes suficiente para ganhos semelhantes aos de animais suplementados. Por outro lado, altura e MF das gramíneas não restringiram o ganho individual (Tabela 1).

O crescimento compensatório envolve a redução na exigência de energia para mantença e o aumento na eficiência do uso da energia metabolizável acima da mantença (Fox et al., 1972). O valor médio de ganho individual observado, $0,957 \mathrm{~kg} / \mathrm{animal} / \mathrm{dia}$, foi superior aos ganhos obtidos por animais da mesma categoria em outros experimentos com animais do

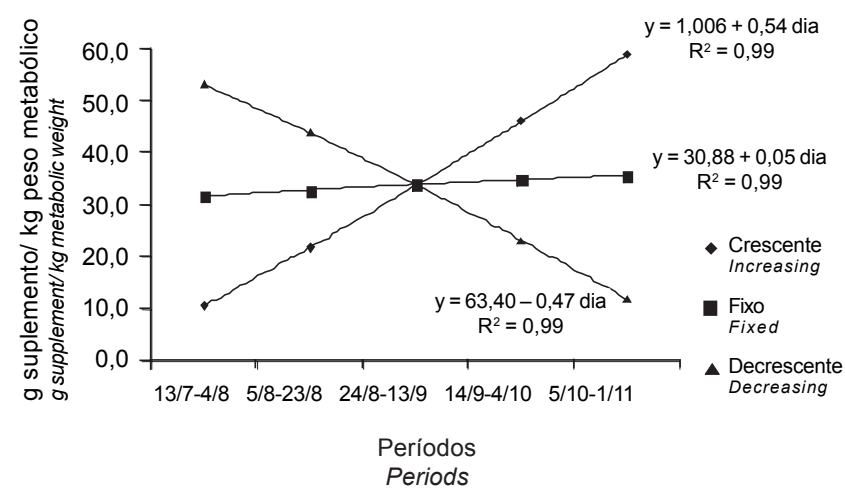

Figura 2 - Quantidade de suplemento consumido, em gramas/kg de peso metabólico, por novilhas de corte submetidas à variação do nível de suplemento durante o ciclo da pastagem de aveia ( $A$. strigosa) mais azevém ( $L$. multiflorum).

Figure 2 - Supplement supplied, in grams $/ \mathrm{kg}$ of metabolic weight, for beef heifers on different supplement levels, during the oat (A. strigosa) plus ryegrass (L. multiflorum) pasture cycle. 
mesmo rebanho, em pastagem de aveia mais azevém, que variaram de $0,597 \mathrm{~kg} / \mathrm{animal} / \mathrm{dia}$ (Restle et al., 2000) a 0,848 (Pilau et al., 2004).

Houve interação entre tratamento e período para a variável quantidade de suplemento consumido/ $\mathrm{kg}$ de peso metabólico $(\mathrm{P}<0,05)$. Na Figura 2, são apresentadas as equações de regressão. No nível 'Crescente', a quantidade consumida de suplemento/kg de peso metabólico variou de 10,6, no período inicial, a 59 $\mathrm{g}$, no final do período de pastejo e foi melhor representada pela equação linear $\left(\mathrm{P}<0,05 ; \mathrm{R}^{2}=0,99\right)$, em que, a cada dia do ciclo, o consumo aumentou em $0,54 \mathrm{~g}$ de suplemento/kg de peso metabólico. A equação de regressão linear representou melhor esta variável no nível 'Fixo' $\left(\mathrm{P}<0,05 ; \mathrm{R}^{2}=0,99\right)$. Os valores foram de 31,6 a $35,8 \mathrm{~g}$ de suplemento/kg de peso metabólico durante o período de pastejo, variação decorrente do aumento do peso vivo dos animais. No nível 'Decrescente', a equação que melhor representou o consumo de suplemento foi a linear decrescente $(\mathrm{P}<0,05$; $\left.\mathrm{R}^{2}=0,99\right)$, com redução de $0,47 \mathrm{~g}$ de suplemento $/ \mathrm{kg}$ de peso metabólico a cada dia de pastejo. Neste tratamento, os valores variaram de 53,2 a 35,5 g/ $\mathrm{kg}$ de peso metabólico $(\mathrm{P}<0,05)$.

Neste experimento, mesmo quando fornecidos $1,5 \%$ do PV de farelo de trigo aos animais, correspondendo a 53,2 e 59,0 g de suplemento $/ \mathrm{kg}$ de peso metabólico, no início e final do período de pastejo, respectivamente, o desempenho individual não foi afetado, contrariando os relatos de Caton \& Dhuyvetter (1997) de que efeitos negativos do suplemento sobre consumo e digestibilidade ruminal seriam notados com fornecimento de suplemento em nível igual ou superior a $0,8 \%$ do PV ou $30 \mathrm{~g}$ de suplemento por $\mathrm{kg}$ de peso metabólico. Pardo et al. (2003) observaram efeito contrário no ganho individual de animais em pastagem natural melhorada recebendo grão de sorgo como suplemento energético a partir do consumo de $40 \mathrm{~g} / \mathrm{kg}$ de peso metabólico.

Os animais, independentemente dos níveis de suplemento, selecionaram forragem de valor semelhante $(\mathrm{P}>0,05)$ em PB, DIVMO, NDT e EM (Tabela 2). Estes parâmetros variaram no decorrer do ciclo da pastagem $(\mathrm{P}<0,05)$, refletindo a mudança da relação folha/colmo nas forrageiras e a maior ou menor facilidade de apreensão de lâminas foliares pelos animais. em pastejo. Além disso, o azevém apresenta maior qualidade que a aveia, observando-se maiores porcentagens de PB e NDT na dieta a partir de 24/08,
Tabela 2 - Valores médios de conteúdo de proteína bruta $(\mathrm{PB})$, digestibilidade in vitro da matéria orgânica (DIVMO), nutrientes digestíveis totais (NDT) e energia metabolizável (EM) da forragem aparentemente consumida e do farelo de trigo

Table 2 - Mean values of crude protein content (CP), in vitro organic matter digestibility (IVOMD), total digestible nutrients (TDN) and metabolizable energy (ME) of apparently intake forage and of wheat bran

\begin{tabular}{lcclc}
\hline Período & PB & DIVMO & NDT & EM \\
Period & $C P$ & IVOMD & TDN & $M E$ \\
\hline 13/07-04/08 & $23,6 \mathrm{~b}$ & $60,0 \mathrm{~b}$ & $54,0 \mathrm{~b}$ & $1,98 \mathrm{~b}$ \\
$05 / 08-23 / 08$ & $26,6 \mathrm{~b}$ & $61,4 \mathrm{~b}$ & $56,0 \mathrm{~b}$ & $2,05 \mathrm{~b}$ \\
$24 / 08-13 / 09$ & $32,3 \mathrm{a}$ & $64,0 \mathrm{ab}$ & $58,2 \mathrm{ab}$ & $2,12 \mathrm{~b}$ \\
$14 / 09-04 / 10$ & $22,5 \mathrm{c}$ & $69,7 \mathrm{a}$ & $63,6 \mathrm{a}$ & $2,34 \mathrm{a}$ \\
05/10-01/11 & $12,8 \mathrm{~d}$ & $61,4 \mathrm{~b}$ & $57,2 \mathrm{~b}$ & $2,09 \mathrm{~b}$ \\
\hline Média & 23,6 & 63,3 & 57,8 & 2,12 \\
Mean & & & & \\
\hline $\begin{array}{l}\text { Farelo de trigo } \\
\text { Wheat bran }\end{array}$ & 22,2 & 70,4 & 65,5 & 2,39
\end{tabular}

$a, b, c$ na mesma coluna, diferem entre si $(P<0,05)$.

$a, b, c$ in the same column, differ $(P<.05)$.

quando a participação desta espécie na mistura foi mais expressiva. Na média do período de pastejo, o teor de PB da forragem aparentemente colhida pelos animais foi superior aos valores encontrados em anos anteriores na mesma área, também com novilhas em pastagem de aveia mais azevém, enquanto os valores médios de DIVMO, NDT e EM se assemelham aos reportados na literatura (Frizzo et al., 2003 b; Pilau et al., 2004; Pilau et al., 2005; Rocha et al., 2003 b). O conteúdo de $\mathrm{PB}$ da forragem aparentemente consumida pelos animais ficou abaixo somente do exigido para animais desta categoria no final do ciclo das gramíneas (12,8\%), evidenciando a importância, nesta ocasião, de um suplemento que venha atender as exigências deste nutriente nos animais.

O farelo de trigo caracterizou-se por valores de NDT, DIVMO e EM superiores aos encontrados na forragem aparentemente colhida pelos animais. $\mathrm{O}$ teor de PB do suplemento somente foi superior ao valor da forragem consumida no final do ciclo da aveia e de azevém. Os valores de PB, DIVMO e NDT no farelo de trigo utilizado por Pilau et al. (2004) foram inferiores, com média de $15,4 \%$ de $\mathrm{PB}, 65,5 \%$ de DIVMO e $62,0 \%$ de NDT, evidenciando a variação na composição química do mesmo subproduto.

$\mathrm{Na}$ Tabela 3, encontram-se as exigências, conforme o NRC (1984), de novilhas de corte de aproxima- 
damente $200 \mathrm{~kg}$, para ganho de $0,918 \mathrm{~kg} / \mathrm{dia}$, e as contribuições nutricionais, nas variações do nível de suplemento utilizado.

Para ganhos individuais de $0,918 \mathrm{~kg}$, o aporte energético fornecido aos animais pelo pasto exclusivo, mesmo abaixo da predição feita pelo NRC (1984), proporcionou ganho médio de $0,957 \mathrm{~kg} / \mathrm{animal} / \mathrm{dia}$, o que pode ser explicado pela restrição nutricional sofrida pelos animais, discutida anteriormente. Sem uso de suplemento, a PB oriunda exclusivamente da pastagem seria suficiente para atender a exigência deste nutriente na faixa de ganho de peso obtido pelos animais, confirmando a afirmação de que, em pastagens temperadas, normalmente há excesso de proteína degradável (Rearte \& Pieroni, 2001). Parte do aporte protéico excedente pode ter contribuído para amenizar um possível déficit energético nos animais mantidos exclusivamente na pastagem (Santos et al., 2005).
As exigências de MS são atendidas quando os animais em pastejo são suplementados com $0,3 \%$ do PV de farelo de trigo. Por outro lado, necessidades de PB dos animais são atendidas exclusivamente em pastagem, pois o teor de $\mathrm{PB}$ da forragem aparentemente consumida é $72 \%$ superior à exigência para esta categoria. O fornecimento de $0,9 \%$ do $\mathrm{PV}$ de farelo de trigo supre as exigências de NDT dos animais em pastejo. As relações pastagem-animalsuplemento seriam melhor entendidas com fornecimento individual do suplemento, algo difícil de ser realizado em condições de pastejo.

$\mathrm{Na}$ Tabela 4 encontram-se as estimativas do consumo de forragem e das taxas de substituição e adição durante o período de pastejo. As novilhas apresentaram consumo médio de $2,14 \%$ do $\mathrm{PV}$, $85,6 \%$ do preconizado pelo NRC (1984) para animais desta categoria, $2,5 \%$ de PV e ganho de $0,918 \mathrm{~kg} / \mathrm{animal} / \mathrm{dia}$.

Tabela 3 - Estimativas de exigências de consumo de matéria seca (MS, kg), proteína bruta (PB, kg e \%), nutrientes digestíveis totais (NDT $\mathrm{kg}$ e \%) e energia metabolizável (EM, Mcal/kg de MS) de novilhas de corte com $200 \mathrm{~kg}$ de PV, segundo o NRC (1984) e das contribuições nutricionais da pastagem e do suplemento

Table 3 - Requirements estimates of intake of dry matter (DM, kg), crude protein (CP, $\mathrm{kg}$ and \%), total digestible nutrients (TDN, $\mathrm{kg}$ and \%) and metabolizable energy (ME, Mcal/ $\mathrm{kg}$ of DM) of beef heifers with $200 \mathrm{~kg} \mathrm{BW}$, expressed as $\mathrm{kg} / \mathrm{day}$ and \% of intake, according to NRC (1984) and nutritional contributions from pasture and wheat bran

\begin{tabular}{|c|c|c|c|c|}
\hline & & $\mathrm{GM}$ & $\begin{array}{l}1 / \text { dia } \\
\text { day }\end{array}$ & \\
\hline & $\begin{array}{l}\mathrm{MS} \\
D M\end{array}$ & $\begin{array}{l}\mathrm{PB} \\
C P\end{array}$ & $\begin{array}{l}\text { NDT } \\
T D N\end{array}$ & $\begin{array}{l}\mathrm{EM} \\
\mathrm{ME}\end{array}$ \\
\hline Exigências (kg/dia e \% da MS) & 4,60 & 0,59 & 3,54 & 2,75 \\
\hline Requirements ( $\mathrm{kg} /$ day and $\%$ of $D M)$ & & $15,1 \%$ & $77,0 \%$ & \\
\hline Fornecido pela pastagem & 4,30 & 1,01 & 2,48 & 0,91 \\
\hline $\begin{array}{l}\text { Pasture supplied } \\
0,3 \% \text { Fornecido pelo suplemento } \\
0.3 \% \text { Supplement supplied }\end{array}$ & 0,56 & 0,12 & 0,37 & 1,35 \\
\hline $\begin{array}{l}0,3 \% \text { Exigência }- \text { fornecido } \\
0.3 \% \text { Requirements }- \text { supplied }\end{array}$ & 4,04 & 0,46 & 3,17 & 1,40 \\
\hline $\begin{array}{l}0,6 \% \text { Fornecido pelo suplemento } \\
0.6 \% \text { Supplement supplied }\end{array}$ & 1,13 & 0,25 & 0,74 & 2,70 \\
\hline $\begin{array}{l}0,6 \% \text { Exigência - fornecido } \\
0.6 \% \text { Requirements }- \text { supplied }\end{array}$ & 3,47 & 0,33 & 2,80 & 0,05 \\
\hline $\begin{array}{l}0,9 \% \text { Fornecido pelo suplemento } \\
0.9 \% \text { Supplement supplied }\end{array}$ & 1,69 & 0,38 & 1,10 & 4,05 \\
\hline $\begin{array}{l}0,9 \% \text { Exigência }- \text { fornecido } \\
0.9 \% \text { Requirements }- \text { supplied }\end{array}$ & 2,90 & 0,21 & 2,43 & - \\
\hline $\begin{array}{l}1,2 \% \text { Fornecido pelo suplemento } \\
1.2 \% \text { Supplement supplied }\end{array}$ & 2,25 & 0,50 & 1,48 & 5,40 \\
\hline $\begin{array}{l}\text { 1,2\% Exigência - fornecido } \\
1.2 \% \text { Requirements }- \text { supplied }\end{array}$ & 2,34 & 0,08 & 2,06 & - \\
\hline $\begin{array}{l}1,5 \% \text { Fornecido pelo suplemento } \\
1.5 \% \text { Supplement supplied }\end{array}$ & 2,82 & 0,63 & 1,85 & 6,75 \\
\hline $\begin{array}{l}\text { 1,5\% Exigência - fornecido } \\
1.5 \% \text { Requirements - supplied }\end{array}$ & 1,77 & - & 1,69 & - \\
\hline
\end{tabular}


Tabela 4 - Estimativas de consumo de matéria seca (MS) da forragem (\%PV), taxa de substituição de MS da forragem por suplemento (kg MS forragem /kg MS suplemento) e taxa de adição do suplemento no consumo total de matéria seca (\%) de novilhas de corte submetidas à variação do nível de suplementação durante o ciclo da pastagem de aveia ( $A$. strigosa) mais azevém (L. multiflorum)

Table 4 - Estimated of total dry matter intake (\%) estimates on dry matter (DM) forage intake (\%LW), replacement level of DM supplement ( $\mathrm{kg} D M$ forage/ $\mathrm{kg} D M$ supplement) by $D M$ forage intake and addition rate of supplement of beef heifers submitted to different supplementation levels, during the oat (A. strigosa) plus ryegrass (L. multiflorum) pasture cycle

\begin{tabular}{lccc}
\hline $\begin{array}{l}\text { Tratamento } \\
\text { Treatment }\end{array}$ & $\begin{array}{c}\text { Consumo de } \\
\text { MS forragem } \\
\text { DM } \\
\text { forage intake }\end{array}$ & $\begin{array}{c}\text { Taxade } \\
\text { substituição } \\
\text { Replacement } \\
\text { rate }\end{array}$ & $\begin{array}{c}\text { Taxade } \\
\text { adição } \\
\text { Addition } \\
\text { rate }\end{array}$ \\
\hline $\begin{array}{l}\text { Sem suplementação } \\
\text { No supplement }\end{array}$ & 2,43 & - & - \\
$\begin{array}{l}\text { Crescente } \\
\text { Increasing }\end{array}$ & 1,96 & 1,0 & 69,5 \\
$\begin{array}{l}\text { Fixo } \\
\text { Fixed }\end{array}$ & 2,24 & 0,3 & 78,2 \\
$\begin{array}{l}\text { Decrescente } \\
\text { Decreasing }\end{array}$ & 1,93 & 0,9 & 35,1 \\
\hline
\end{tabular}

Os efeitos de adição e substituição do consumo de forragem pelo de suplemento foram bastante evidentes. As taxas de substituição foram de 1,0; 0,3 e 0,9 kg de MS da forragem para cada kg de MS do farelo de trigo fornecido às novilhas dos tratamentos 'Crescente', 'Fixo' e 'Decrescente', respectivamente. Com estas taxas de substituição, os incrementos na carga animal (CA) foram de 24,6; 4,0 e 9,0\% para os níveis 'Crescente', 'Fixo' e 'Decrescente', respectivamente. Pilau et al. (2004) observaram que a suplementação com $1,5 \%$ do PV de farelo de trigo em pastagem de aveia mais azevém ocasionou taxa de substituição de 0,6 , proporcionando incremento de $32,2 \%$ na CA. Revisando a literatura, Minson (1990) observou taxa de substituição média de 0,69 , com animais de diferentes categorias. Em pastagens temperadas, é esperado que o efeito do suplemento seja mais substitutivo que aditivo (Rearte \& Pieroni, 2001).

$\mathrm{O}$ efeito aditivo sobre o consumo total de MS foi de 69,5; 78,2 e 35,1\% nos níveis 'Crescente', 'Fixo' e 'Decrescente', respectivamente, e não resultou em maior ganho individual (Figura 1). Pilau et al. (2004) encontraram consumo médio estimado, em animais não-suplementados de 3,9\% do PV em novilhas em pastagem de aveia e azevém. A variabilidade dos parâmetros incluídos no cálculo da estimativa de consumo de MS, adotando-se a técnica do desaparecimento de forragem, ocasiona muitas fontes de erro, subestimando o consumo em 10 a $20 \%$, quando em comparação com o método que utiliza óxido de cromo. Mesmo assim, é considerada uma técnica adequada para se estudar o efeito da suplementação em pastagens, visto que não é necessário incorporar os processos digestivos nos cálculos (Astigarra, 1997).

Na Figura 3 são apresentados os resultados de carga animal (CA), que foi semelhante entre os tratamentos $(\mathrm{P}>0,05)$. Os valores de substituição encontrados não foram suficientes para alterar a $\mathrm{CA}$, que variou entre os períodos de avaliação $(\mathrm{P}<0,05)$. Esta variação é melhor representada pela equação cúbica, em que $\mathrm{CA}=82,02+82,65$ dia-1,60 dia ${ }^{2}+0,01$ $\mathrm{dia}^{3}\left(\mathrm{R}^{2}=0,64\right)$. Do ponto de vista prático, isto não é desejável, pois há alternância de períodos com cargas altas e baixas, intensificando o manejo do rebanho. A oscilação na capacidade de suporte da pastagem ao longo do seu período de utilização decorre da estacionalidade de produção das espécies, provocada pelas variações das condições climáticas. Assim, a carga animal deve variar de acordo com a taxa de crescimento da forrageira para que seja mantida constante a oferta de forragem desejada. Foi observado por Pilau et al. (2004) que o nível 1,5\% do PV de suplemento é suficiente para a carga animal tornar-se independente da taxa de acúmulo de MS da forrageira. Com nível fixo de suplemento $(0,9 \%$ do PV) inferior ao

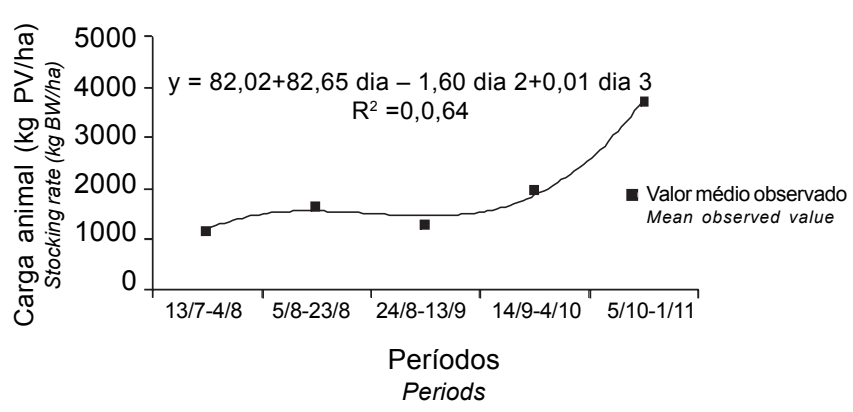

Figura 3 - Carga animal (CA, kg PV/ha) em pastagem de aveia (A. strigosa) mais azevém (L. multiflorum) utilizada por novilhas de corte.

Figure 3 - Stocking rate (SR, $\mathrm{kg} L W / \mathrm{ha}$ ) for beef heifers on oat (A. strigosa) plus ryegrass (L. multiflorum) pasture. 
valor de $1,5 \%$ mencionado por Pilau et al. (2004) e quantidade de suplemento correspondente a $1,5 \%$ do PV, utilizado somente no início (nível 'decrescente') e no final (nível 'crescente') do ciclo das forrageiras, a carga animal oscilou e foi dependente da variação da taxa de acúmulo de forragem.

A pastagem suportou, em média, $1.961 \mathrm{~kg} / \mathrm{ha}$ de PV durante o período de pastejo, valor superior aos reportados na literatura, que variaram de $858 \mathrm{~kg} / \mathrm{ha}$ de PV (Restle et al., 2000) a $1.392 \mathrm{~kg} /$ ha de PV (Frizzo et al., 2003). Valores de carga animal superiores a $1.500 \mathrm{~kg} /$ ha de PV são característicos no Rio Grande do Sul, em pastagens de estação quente, como o milheto (Pennisetum americanum) (Schwartz et al., 2003) e não de pastagens temperadas. O potencial de produção das espécies temperadas, como aveia e azevém, é ainda pouco conhecido, sobretudo em razão das variações nas taxas de acúmulo de MS, que são extremamente dependentes das condições climáticas.

O peso vivo (PV) e o escore de condição corporal (ECC) ao final do período de pastejo são de fundamental importância para se estabelecer a idade ao primeiro acasalamento de novilhas. Os GMD obtidos proporcionaram PV final de $253 \mathrm{~kg}$. O peso mínimo recomendado pelo NRC (1996) para o primeiro acasalamento de novilhas cruzadas Bos taurus $\mathrm{x}$ Bos indicus é de $65 \%$ do peso adulto, ou seja, $450 \mathrm{~kg}$, no rebanho utilizado. Com GMD de $0,957 \mathrm{~kg} / \mathrm{animal} / \mathrm{dia}$, no final do período de pastejo, as novilhas apresentaram $57 \%$ do peso adulto. O ganho realizado, $107 \mathrm{~kg}$, correspondente a $23,8 \%$ do peso adulto. O peso das novilhas, no início do período de pastejo deveria ser de $41,2 \%$ para que fosse atingido o 'peso alvo' no final da utilização da pastagem. $\mathrm{O}$ peso inicial, no entanto, foi de $149 \mathrm{~kg}$, correspondente a $33 \%$ do peso adulto. Considerando-se o uso exclusivo de pastagens temperadas, que o GMD obtido pode ser considerado alto e que $42 \%$ do peso adulto corresponde a $185 \mathrm{~kg}$, é questionável a afirmação de Moraes \& Lobato (1993) de que até o limite inferior de $143 \mathrm{~kg}$ aos 150 dias de idade das bezerras, é possível alcançar o primeiro serviço aos 14-15 meses. As novilhas necessitariam ganhar, neste experimento, em média $39,5 \mathrm{~kg}$ até o início do período de acasalamento preconizado (15/11), praticamente inviabilizando seu acasalamento nesta ocasião, pois necessitariam GMD de 2,6 kg/dia.

Para uma mesma taxa de ganho de peso, não houve mudança no ECC $(\mathrm{P}>0,05)$ entre os níveis de suplementação. Os animais ganharam apenas 0,1 ponto no ECC durante 112 dias de pastejo, com escore médio inicial de 2,8, o que contraria a afirmação de que animais recebendo suplementação energética em pastagens com altos teores de proteína bruta tendem a acumular gordura mais precocemente em relação aos exclusivamente em pastejo (Frizzo et al., 2003). O resultado pode ser explicado pelo fato de os animais terem passado por uma restrição alimentar anterior ao período experimental, fazendo com que as novilhas realizassem um ganho compensatório, com duração de até 90 dias (NRC, 1996), caracterizado por maior crescimento muscular. O maior ECC em animais suplementados, no final do período de pastejo, é determinado pela composição do ganho de peso. Portanto, para que as novilhas passassem a depositar gordura subcutânea e elevassem o ECC, haveria 22 dias até o final do período de pastejo, tempo insuficiente para incremento no ECC. Para uma mudança de $107 \mathrm{~kg}$ no PV, o ECC permaneceu constante, entretanto, Pilau et al. (2003), em novilhas recebendo suplementação em pastagem de aveia mais azevém, registraram maior peso corporal (164 kg) no início do experimento e um ponto adicional no ECC, com mudança de $115 \mathrm{~kg}$ no PV, durante o período de pastejo.

O ganho de peso total por área (GPA) (Tabela 5) não apresentou diferença $(\mathrm{P}>0,05)$ entre os níveis de suplementação, apesar de ter sido 34,29 e $25 \%$ superior nos níveis 'Crescente', 'Fixo' e 'Decrescente', respectivamente, em relação ao nível 'Sem Suplemento', que produziu um total de $774,6 \mathrm{~kg} /$ ha de $\mathrm{PV}$.

A suplementação afetou $(\mathrm{P}<0,05)$ o GPA apenas no período correspondente ao final do ciclo da pastagem, quando o GPA no nível 'Sem Suplementação' foi inferior $(\mathrm{P}<0,05)$ ao 'Crescente', e não diferiu dos demais níveis de suplemento. O GPA é obtido pelo produto do GMD e do número de animais por dia, por hectare. Então, as relações entre GMD, CA e período de pastejo podem maximizar ou minimizar a produção total por área, pois possuem relação muito estreita com a economicidade do sistema em estudo, uma vez que níveis muito elevados de insumos, como alta quantidade de suplemento, para assegurar elevado GPA, podem resultar em prejuízo econômico (Macari et al., 2003).

O GPA médio obtido (946 kg de PV/ha), é superior aos ganhos encontrados por vários autores em pastagens de inverno, variando de 336 (Pilau et al., 
Tabela 5 - Ganho de peso por área (GPA, kg PV/ha) de novilhas de corte em pastagem de aveia ( $A$. strigosa) mais azevém (L. multiflorum)

Table 5 - Body gain per area (AWG, $\mathrm{kg}$ LW/ha) of beef heifers grazing oat (A. strigosa) plus ryegrass (L. multiflorum) pasture

\begin{tabular}{|c|c|c|c|c|c|c|}
\hline \multirow[t]{2}{*}{$\begin{array}{l}\text { Tratamento } \\
\text { Treatment }\end{array}$} & \multicolumn{5}{|c|}{$\begin{array}{l}\text { Período } \\
\text { Period }\end{array}$} & \multirow[t]{2}{*}{$\begin{array}{l}\text { Total } \\
\text { Total }\end{array}$} \\
\hline & $13 / 7-4 / 8$ & $5 / 8-23 / 8$ & $24 / 8-13 / 9$ & $14 / 9-4 / 10$ & $5 / 10-1 / 11$ & \\
\hline $\begin{array}{l}\text { Sem suplementação } \\
\text { Not supplemented }\end{array}$ & 115,4 & 218,4 & 144,3 & 192,7 & $103,8 \mathrm{~b}$ & 774,6 \\
\hline $\begin{array}{l}\text { Crescente } \\
\text { Increasing }\end{array}$ & 110,8 & 229,7 & 135,9 & 206,3 & $353,6 \mathrm{a}$ & $1.039,3$ \\
\hline & 144,4 & 199,8 & 111,2 & 248,2 & $295,8 \mathrm{ab}$ & $1.000,4$ \\
\hline $\begin{array}{l}\text { Decrescente } \\
\text { Decreasing }\end{array}$ & 151,6 & 231,8 & 160,3 & 201,9 & $225,1 \mathrm{ab}$ & 970,7 \\
\hline $\begin{array}{l}\text { Média } \\
\text { Average }\end{array}$ & $130,6 \mathrm{c}$ & $219,9 a$ & $137,9 \mathrm{bc}$ & $212,3 \mathrm{ab}$ & $244,6 \mathrm{a}$ & \\
\hline $\mathrm{CV}(\%)$ & 27,64 & 44,77 & 30,27 & 22,75 & 23,17 & \\
\hline
\end{tabular}

a, b, c na mesma linha, diferem entre si $(P<0,05)$; $a, b, c$ within a row, differ $(P<.05)$.

2004) a $761 \mathrm{~kg}$ de PV/ha (Roso \& Restle, 2000). O GPA encontrado por estes últimos autores está relacionado basicamente ao maior período de utilização da pastagem.

\section{Conclusões}

A suplementação energética de novilhas com baixo escore de condição corporal, mantidas em pastagem cultivada de aveia mais azevém não afeta o desempenho dos animais.

A variação de níveis de suplementação energética com farelo de trigo no decorrer do ciclo da pastagem de aveia e azevém não interfere no ganho médio diário, no escore de condição corporal dos animais e na produção de peso vivo por área e na carga animal.

\section{Literatura Citada}

ASSOCIATION OF OFFICIAL ANALITICAL CHEMISTS AOAC. Official methods of analysis. 15.ed. Arlington: 1990. 1298 p.

ASTIGARRA, L. Técnicas para la medición del consumo de rumiantes en pastoreo. In: JOBIM, C.C.; SANTOS, G.T.; CECATO, U. (Eds.). Simpósio sobre avaliação de pastagens com animais. Maringá: Cooper Graf. Artes Gráfica Ltda., 1977. p.1-23.

BODINE, T.N.; PURVIS II, H.T.; LALMAN, D.L. Effects of supplement type on animal performance, forage intake, digestion, and ruminal measurements of growing beef cattle. Journal of Animal Science, v.79, n.4, p.1041-1051, 2001.

CATON, J.S.; DHUYVETTER, D.V. Influence of energy supplementation on grazing ruminants: requirements and responses. Journal of Animal Science, v. 75, n.4, p.533-542, 1997.
EMPRESA BRASILEIRA DE PESQUISA E AGROPECUÁRIA - EMBRAPA. Centro Nacional de Pesquisa de Solos. Sistema brasileiro de classificação de solos. Braślia: EMBRAPA. Rio de Janeiro, 1999. 412p.

EUCLIDES, V.P.B.; MACEDO, M.C.M.; OLIVEIRA, M.P. Avaliação de diferentes métodos de amostragem sob pastejo. Revista Brasileira de Zootecnia, v.21, n.4, p.691-702, 1992.

FOX, D.G.; JOHNSON, R.R.; PRESTON, R.L. et al. Protein and energy utilization during compensatory growth in beef cattle. Journal of Animal Science, v.38, p.437-445, 1972.

FREITAS, F.K.; ROCHA, M.G.; RESTLE, J. et al. Suplementação energética na recria de fêmeas de corte em pastagem cultivada de inverno - dinâmica da pastagem. Revista Brasileira de Zootecnia, no prelo, 2005.

FRIZZO, A.; ROCHA, M.G.; RESTLE, J. et al. Suplementação energética na recria de bezerras de corte mantidas em pastagem de inverno. Revista Brasileira de Zootecnia, v.32, n.3, p.643-652, 2003.

FRIZZO, A.; ROCHA, M.G.; RESTLE, J. et al. Produção de forragem e retorno econômico da pastagem de aveia e azevém sob pastejo com bezerras de corte submetidas a níveis de suplementação energética. Revista Brasileira de Zootecnia, v.32, n.3, p.632-642, 2003 b.

GALLOWAY, D.L.; GOETSCH, A.L.; FOSTER, L.A. et al. Feed intake and digestion by Holstein steers fed warm or cool season grass hays with corn, dried molasses, or wheat middlings. Journal of Dairy Science, v.74, n.3, p.1038-1046, 1991.

GRISE, M.M.; CECATO, U.; MORAES, A. et al. Avaliação da composição química e da digestibilidade in vitro da mistura aveia IAPAR 61 (Avena strigosa Schreb.) + ervilha forrageira (Pisum arvense L.) em diferentes alturas sob pastejo. Revista Brasileira de Zootecnia, v.30, n.3, p.659-665, 2001.

HILLESHEIM, A. Fatores que afetam o consumo e perdas de capim elefante (Pennisetum purpureum SCHUM.) sob pastejo. Piracicaba: Escola Superior de Agricultura "Luiz de Queiroz”, 1987.94p. Dissertação (Mestrado em Agronomia) - Escola Superior de Agricultura "Luiz de Queiroz"/Universidade de São Paulo, 1987.

HODGSON, J. Grazing management. Science into practice. Essex: Longman Group UK Ltda, 1990. p.203. 
LOWMAN, B.G.; SCOTT, N.; SOMERVILlE, S. Condition scoring beef cattle. Edinburgh: East of Scotland College of Agriculture, 1973. 8p.

MACARI, S.; PILAU, A., ROCHA, M.G. et al. Carga animal e produção por área em pastagem de inverno com suplementação energética para bezerras de corte. In: REUNIÃO ANUAL DA SOCIEDADE BRASILEIRA DE ZOOTECNIA, 40., 2003, Santa Maria. Anais... Santa Maria: Sociedade Brasileira de Zootecnia/Macromedia, [2003]. CD-ROM. Forragicultura.

MINISTRY OF AGRICULTURE, FISHERIES AND FOOD MAFF. Energy allowances and feed systems for ruminants. London: 1977. 79p. (Technical Bulletin, 33)

MINSON, D.L. Forage in ruminant nutrition. San Diego: Academic Press, 1990. 483p.

MORAES, A.A.S.; LOBATO, J.F.P. Efeito de duas idades de desmame no desenvolvimento de terneiros de corte. Revista Brasileira de Zootecnia, v.22, n.6, p.885-892, 1993.

MORENO, J.A. Clima do Rio Grande do Sul. Porto Alegre: Secretaria da Agricultura, 1961.41p.

MOTT, G.O.; LUCAS, H.L. The design conduct and interpretation of grazing trials on cultivated and improved pastures. In: INTERNATIONAL GRASSLAND CONGRESS, 6., 1952, Pensylvania. Proceedings... Pensylvania: SCP, 1952. p.13801395.

NATIONAL RESEARCH COUNCIL - NRC. Nutrient requirements of beef cattle. 7.ed. Washington D.C., 1996. 90p.

NATIONAL RESEARCH COUNCIL-NRC. Nutrient requirement of beef cattle. 6.ed. Washington, D.C.: National Academy Press, 1984. 90p.

PARDO, R.M.P.; FISCHER, V.; BALBINOTTI, M. et al. Níveis crescentes de suplementação energética sobre o desenvolvimento de novilhos mantidos em pastagem natural na encosta do sudeste do Rio Grande do Sul. Revista Brasileira de Zootecnia, v.32, n.6, p.1397-1407, 2003.

PILAU, A.; ROCHA, M.G.; RESTLE, J. et al. Development of beef heifers submitted to energetic supplementation levels in cultivated winter pasture: live weight and body condition. In: WORLD CONFERENCE ON ANIMAL PRODUCTION, 19., 2003, Porto Alegre. Proceedings... Porto Alegre: ALPA, [2003]. CD-ROM.

PILAU, A.; ROCHA, M.G.; RESTLE, J. et al. Recria de novilhas de corte com níveis de suplementação energética em pastagem de aveia preta e azevém. Revista Brasileira de Zootecnia, v.33, n.6, p.2104-2113, 2004.

PILAU, A.; ROCHA, M.G.; RESTLE, J. et al. Desenvolvimento de novilhas de corte recebendo ou não suplementação energética em pastagem hibernal sob diferentes disponibilidades de forragem. Revista Brasileira de Zootecnia, no prelo, 2005.
POPPI, D.P.; McLENNAN, S.R. Protein and energy utilization by ruminants at pasture. Journal of Animal Science, v.73, n.1, p.278-290, 1995.

PÖTTER, L. Curso de sistemas de produção. Santa Maria: Curso de Pós-graduação em Zootecnia, 1998. 15p.

REARTE, D.H.; PIERONI, G.A. Supplementation of temperate pastures. In: INTERNATIONAL GRASSLAND CONGRESS, 19., 2001, São Pedro. Proceedings... São Pedro: Sociedade Brasileira de Zootecnia, 2001. p.679-689. 2001.

RESTLE, J.; ROSO, C.; SOARES, A. et al. Produtividade animal e retorno econômico em pastagem de aveia preta mais azevém adubada com fontes de nitrogênio em cobertura. Revista Brasileira de Zootecnia, v.29, n.2, p.357-364, 2000.

ROCHA, M.G.; RESTLE, J.; PILAU, A. et al. Produção animal e retorno econômico da suplementação em pastagem de aveia e azevém. Ciência Rural, v.33, n.3, p.85-93, 2003.

ROCHA, M.G.; RESTLE, J.; FRIZZO, A. et al. Alternativas de utilização da pastagem hibernal para recria de bezerras de corte. Revista Brasileira de Zootecnia, v.32, n.2, p.383392, 2003b.

ROSO, C.; RESTLE, J. Aveia preta, triticale e centeio em mistura com azevém. 2. Produtividade animal e retorno econômico. Revista Brasileira de Zootecnia, v.29, n.1, p.85-93, 2000.

SANTOS, D.T.; ROCHA, M.G.; QUADROS, F.L.F. et al. Suplementos energéticos para recria de novilhas de corte em pastagens anuais. Desempenho animal. Revista Brasileira de Zootecnia, v.34, n.1, p.209-219, 2005.

STATISTICAL ANALYSES SYSTEM - SAS. SAS/STAT user's guide: statistics. 4.ed. Version 6, Cary: 1996. v.2, 943p.

SCHWARTZ, F.; ROCHA, M.G.; VÉRAS, M.M. et al. Manejo do milheto (Pennisetum americanum LEEKE) sob pastejo de ovinos. Revista Brasileira de Agrociência, v.9, n.2, p.95-186, 2003.

TAMBARA, A.A.C.; OLIVO, C.J.; PIRES, M.B.G. et al. Avaliação in vivo da digestibilidade da casca do grão de soja moída com ovinos. Revista Ciência Rural, v.25, n.2, p.283-287, 1995.

TILLEY, J.M.A.; TERRY, R.A.A. Two stage technique for the "in vitro" digestion of forage crops. Journal of British Grassland Society, v.18, n.2, p.104-111, 1963. 